\title{
High scores but low skills ${ }^{\text {is }}$
}

\author{
Liqun Liu ${ }^{\mathrm{a}}$, William S. Neilson ${ }^{\mathrm{b}, *}$ \\ a Private Enterprise Research Center, Texas AEM University, United States \\ b Department of Economics, University of Tennessee, Knoxville, United States
}

\section{A R T I C L E I N F O}

\section{Article history:}

Received 28 April 2010

Received in revised form 9 December 2010

Accepted 10 December 2010

\section{JEL classification:}

I21

I 28

$\mathrm{J} 24$

\section{Keywords:}

College admission

Standardized test

Tournament

Income inequality

Teaching to the test

\begin{abstract}
A B S T R A C T
In this paper college admissions are based on test scores and students can exert two types of effort: real learning and exam preparation. The former improves skills but the latter is more effective in raising test scores. In this setting the students with the lowest skills are no longer the ones with the lowest aptitude, but instead are the ones closest to the borderline for college admission. Increased access to college leads to greater income inequality between college graduates and non-graduates. Overall, the ability to study for the test leads to higher expected test scores but lower skills.
\end{abstract}

(C) 2010 Elsevier Ltd. All rights reserved.
"The tutors may not actually help you speak better English, but your scores will certainly be better." - an anonymous student

“In my heart, I don't agree with these tutoring practices, but when everyone else takes their classes and your children don't, you are afraid they won't be as competitive." - an anonymous parent

\section{Introduction}

Every year, graduating high school students compete with each other for a limited number of college

\footnotetext{
is We thank Scott Carrell, David Figlio, Scott Gilpatric, Steve Pischke, Philip Trostel, Ron Zimmer, seminar participants at West Virginia University, conference participants at PET 2009, and two referees for insightful comments and discussions. We also thank Amy Hopson for excellent research assistance.

* Corresponding author.

E-mail addresses: lliu@neo.tamu.edu (L. Liu), wneilson@utk.edu (W.S. Neilson).
}

freshman seats. The reason for such competition is the so-called "college premium" that can be broadly defined to include not only the wage premium for college graduates compared to high school graduates, but also the job satisfaction and social status associated with a college degree. One channel through which pre-college students compete is testing. In the extreme case admission is based solely on each student's score on a collegeentrance exam, and such admission policies can be found in Austria, China, and Ireland, but not in the U.S. or the U.K. ${ }^{1}$

\footnotetext{
${ }^{1}$ Helms (2008) compares college admission systems worldwide. Some countries, including France, Austria, Ireland, and Egypt base admissions solely on student performance on a national secondary leaving examination. Other countries use national university entrance examinations rather than secondary leaving examinations, and countries that consider only the national entrance exam score include China, Iran, and the Republic of Georgia. Japan, Russia, Finland, Israel, and les Grandes Ecoles in France use the centralized exam plus an institutional exam. In contrast to these, the United States and the United Kingdom consider test scores merely as one component of the student's application portfolio. At the other end of
} 
College entrance examinations, or standardized tests in general, are designed in such a way that, other things being equal, students with higher skills would score higher on such tests. Therefore, it is somewhat surprising to hear college professors and employers of high school graduates complain about a situation in which the average test score gets higher from one cohort to another, but the average level of skills actually becomes lower. ${ }^{2}$ This phenomenon, dubbed "high scores but low skills," is widely observed, but is especially prevalent in cultures that place particularly high values on education and in countries that have admission policies solely based on college entrance examination scores. ${ }^{3}$ Then why do standardized tests designed to test a student's skills generate scores that can misrepresent his/her skill level? How can we explain the phenomenon of "high scores but low skills?"

Standardized tests by their very nature can only test a subset of useful skills. As a result, while a well-balanced effort at improving overall skills helps raise the test score, it is usually not as effective as a more focused approach: teaching/studying to the test. There is evidence that drilling students on content known to be on a test can significantly improve the students' performance on the test, but the resulting high test scores do not necessarily translate into corresponding knowledge and skills. ${ }^{4}$

In this paper, we distinguish between two kinds of effort by a pre-college student in her preparation for application to college: the effort on real learning focusing on skill improvement, and the effort on exam preparation focusing on raising test scores. The latter effort is more effective in raising test scores but less efficient in improving skill levels than the former. For example, to prepare for the verbal part of a standardized test, one can either read a selection of classic novels which include many of the literary words emphasized in the test or directly memorize a list of test words. While the former strategy exposes students to some of the vocabulary, it also provides lessons about the human

the spectrum, in Norway the college admission process uses no exams at all.

2 Despite the fact that our analysis applies more closely to countries that base admission solely on the standardized test than it does to the U.S., American studies provide some evidence that students have become increasingly ill-prepared for college. The 2007-2008 HERI Faculty Survey (DeAngelo et al., 2009) gathered responses from 22,562 full-time faculty members at 372 4-year colleges and universities throughout the United States. Only $44.2 \%$ felt that most students are well-prepared academically, and $36.4 \%$ agreed that most of the students they teach lack the basic skills for college level work. The problems are most severe at 4-year public colleges, with more (49.7\% vs. 30.6\%) regarding students as lacking basic skills than being well-prepared. At the same time, though, the 2008 HERI survey of 240,580 first-time freshmen at 340 American colleges and universities (Pryor et al., 2008) found that $69.5 \%$ of freshmen rated themselves at least above-average academically, and this number was $61.0 \%$ for 4 -year public colleges. The most compelling evidence, perhaps, comes from the 2003 National Assessment of Adult Literacy, which found that Prose and Document scores both fell significantly among college graduates between 1992 and 2003, with average scores in both categories falling in the intermediate, not the proficient, range. See National Center for Educational Statistics (2006).

3 Complaints about high scores but low skills are much more widely spread in China than in the U.S., most likely because in China test scores play a much more important role in college admission (e.g. Li, 2005).

4 See Smith and Fey (2000) and Burger and Krueger (2003). condition and introduces the reader to different cultures, places, and times. On the other hand, the latter strategy is much more effective in preparing for the specific exam. ${ }^{5}$

In a tournament model of college admissions with these two types of effort, we predict a very robust phenomenon of high scores but low skills. More precisely, we compare a benchmark case in which only real learning is possible to a setting in which both types of effort are possible, and find that the ability to prepare for the college entrance examination leads to higher scores but lower skills, and this effect is amplified as the college premium increases. ${ }^{6}$ The reason is that higher college premiums increase the payoffs from studying for the college entrance examination, so students substitute away from learning and toward test preparation. The ability to prepare for the college entrance examination does not change who gets into college, though, with higher aptitude students having higher expected test scores and greater chances of admission in both cases.

Our model also generates some other, surprising findings. One concerns the relationship between aptitude and skills. When test preparation is not possible there is a direct relationship between aptitude and skills: higher aptitude students learn more and acquire more skills. In particular, the students with the lowest skills are the ones with the lowest aptitude. When test preparation is possible, however, this direct relationship fails, and now the students with the lowest skills are the ones who are nearest the cutoff for getting into college. The reason is that these borderline students have the most at stake from test preparation so they concentrate their efforts there, while those with the lowest aptitude have little chance of getting into college and so concentrate on acquiring skills.

A second surprising implication of the model concerns access to college. Standard analysis suggests that increasing access to higher education would reduce income inequality between college graduates and non-college graduates, as the changes in supply reduce the wages of graduates and increase the relative wages of non-graduates. When test preparation is not possible, a second mechanism works in the same direction, with increased access enhancing the expected marginal payoff (in terms of expected admission to college) from skill acquisition for low aptitude students but decreasing the expected marginal payoff for high aptitude students, thereby reducing the productivity of college graduates and increasing the productivity of non-graduates. When test preparation is possible, though, this second mechanism gets reversed. The increased access causes low aptitude students to substitute toward test preparation and away from learning, so that they acquire fewer skills. At the same time, increased access makes

\footnotetext{
5 By exploring the consequences of having misaligned incentives that induce students to study for a high-stakes exam instead of engaging in activities that directly increase workplace productivity, this paper complements the literature on optimal incentives in a multitask, principal-agent environment, which is primarily concerned with providing efficient incentives when agents devote effort to different tasks (e.g. Baker, 2002; Holmstrom \& Milgrom, 1991; Lazear, 2006).

6 The college premium might increase because of major (e.g. Kelly, O'Connell, \& Smyth, 2010) or because of the relevance of the major for the occupation (e.g. Yakusheva, 2010).
} 
high aptitude students surer of admission, freeing them to substitute toward learning and away from test preparation, increasing their skills. Consequently, when students can prepare explicitly for college entrance examinations, increased access to higher education can increase, rather than reduce, inequality.

The results of this paper are particularly informative in light of the empirical findings of Hoxby (2009) and Bound, Hershbein, and Long (2009). ${ }^{7}$ Bound et al. find that more students engaged in test preparation in 2004 than in 1992, whether through formal class work or on their own. They also find that increased competition for college slots has not led to any increase in real earnings, suggesting that the pressure to perform better on entrance examinations is not translating into students learning more. This is the "low skills" part of the phenomenon. Hoxby finds that over the past quarter century mean SAT/ACT percentile scores have risen for the $80 \%$ of colleges ranked highest according to selectivity. This is the "high scores" phenomenon. Nevertheless, and contrary to what one would expect by focusing only on the very selective schools, college admissions in the United States have become less selective over the past four decades. In light of our results, the decreased college selectivity could provide a contributing explanation for increased wage inequality during that period.

Section 2 introduces the college admission tournament model and notation. Section 3 explores how expected test scores and skill levels vary with aptitude, Section 4 explores what happens when colleges lower the admission standard, and Section 5 examines the impact of changes in the college premium. Finally, Section 6 establishes the high scores but low skills phenomenon, showing that when the admission standard is held constant, the ability to substitute test preparation for real learning leads students at every aptitude level to have higher expected test scores but fewer skills. Section 7 offers concluding remarks, and all proofs are collected in an appendix.

\section{College admission tournaments}

A society contains a unit mass of students indexed by their aptitude $a>0$. Individuals can expend costly effort on two activities, and the effectiveness of these activities is determined by aptitude. One of the activities is effort devoted to real learning, denoted $e_{L}$, and it impacts the individual's pre-college productivity. In particular, if an individual with aptitude $a$ exerts $e_{L}$ units of effort on real learning, her pre-college productivity is $f\left(a e_{L}\right)$, where $f^{\prime}>0$

\footnotetext{
7 The work in this paper is complementary to the work of Epple, Romano, and Sieg (2002), Epple, Romano, and Sieg (2003), Epple, Romano, and Sieg (2006), Epple, Romano, and Sieg (2008). In their papers students differ in income and ability, and ability is measured by a test score. Our model separates ability from test scores, and derives as a result that higher ability students earn higher test scores, on average. The model of Epple et al. treats the distribution of test scores as exogenous where we treat it as endogenous, determined by ability and two types of effort. On the other hand, we consider a single college and treat its enrollment capacity as exogenous, while Epple et al. consider a hierarchy of colleges competing for the best students. Such a hierarchy is compelling, but well beyond the scope of this paper, and a melding of the two models is worthy of further research.
}

and $f^{\prime \prime}<0$. In the remainder of the paper we refer to the value of $f\left(a e_{L}\right)$ as skills. The other activity is explicit preparation for the college entrance exam, and this effort is denoted $e_{E}$. Unlike real learning, test preparation has no direct impact on skills. ${ }^{8}$ The total cost of effort is given by the function $c\left(e_{E}+e_{L}\right)$, with $c^{\prime}>0$ and $c^{\prime \prime}>0$.

The reason for exerting effort toward test preparation is that it improves the chances of getting into college. College, in turn, provides an increment $\pi(a)$ to productivity, so that an individual with skill level $y$ and aptitude $a$ has post-college productivity $y+\pi(a)$, where $\pi(a)$ is assumed to be net of college costs. The college premium is assumed to be weakly increasing in aptitude, $\pi^{\prime} \geq 0 .{ }^{9} \pi(a)$ can be decomposed as $\pi(a)=\pi_{0}+q(a)$, where $\pi_{0}$ is the average college premium and $q(a)$, with $q^{\prime} \geq 0$, represents aptitude's contribution to college premium. An individual who does not attend college experiences no gain in productivity, so pre-college and post-college productivity levels are the same. Labor markets are competitive and workers are paid according to their productivity.

College admissions are based solely on entrance exam scores. In particular, the college sets a threshold score $s$, and any student who scores $s$ or higher gains admittance and realizes the college premium. ${ }^{10}$ A student's test score $t$ is a random variable influenced by her aptitude $a$, effort $e_{L}$ on learning, and effort $e_{E}$ on test preparation, and given by

$t=a\left(\theta e_{E}+e_{L}\right)+\varepsilon$,

where $\theta$ is a parameter governing the relative effectiveness of the two types of effort for raising the test score, and $\varepsilon$ is a mean-zero random variable with distribution function $G(\cdot)$ and density function $g(\cdot) .{ }^{11}$ Note that both types of effort impact test scores, and that aptitude magnifies the impact of effort in the same way as it does in the skill production function. Because the effort on test preparation does not contribute to productivity, for a student to exert any test preparation effort it must be the case that $\theta>1$ so that direct test preparation has a greater effect on test scores than general (but productivity-enhancing) learning.

\footnotetext{
8 For simplicity, we assume test preparation has no effects on skill formation. This assumption is not critical though. All we need is for test preparation to be more effective in raising test scores but less effective in raising skills than genuine learning.

9 The college premium may or may not be independent of the precollege skill level. Grogger and Eide (1995) find evidence that skills attained prior to college, as measured by standardized test scores and high school grades, have no effect on the change in the college wage premium for men. On the other hand, changes in the college major distribution explain a significant portion of the rise in the male college wage premium. As for what determines the college premium or rate of return to schooling in general, two theories - human capital and signaling - have been advanced in the literature (see, for example, Groot \& Oosterbeek, 1994, and Weiss, 1995). Fang (2006) finds that human capital enhancement accounts for at least two-thirds of the college wage premium, with the remainder arising from ability signaling.

10 Ockert (2010) describes a closely-related centralized admissions procedure in Sweden, where students are scored and ranked nationally, and those that exceed a threshold gain admission to college.

11 Epple, Romano, Sarpça, and Sieg (2006) also assume that colleges observe ability imperfectly, but in the context of a negotiation model where colleges compete for students instead of a tournament model in which students compete for admission.
} 
if

The student is admitted to college if $t \geq s$, which occurs

$\varepsilon \geq s-a\left(\theta e_{E}+e_{L}\right)$

Consequently, the probability of acceptance is

$1-G\left(s-a\left(\theta e_{E}+e_{L}\right)\right)$

Besides having a mean of zero, the density function $g$ is assumed to be symmetric and single-peaked, for example bell-shaped, so that $g^{\prime}(\varepsilon)>0$ when $\varepsilon<0, g^{\prime}(\varepsilon)<0$ when $\varepsilon>0$, and $g^{\prime}(0)=0$.

The objective of a student with aptitude $a$ is to choose $e_{L}$ and $e_{E}$ to maximize

$f\left(a e_{L}\right)+\pi(a)\left[1-G\left(s-a\left(\theta e_{E}+e_{L}\right)\right)\right]-c\left(e_{E}+e_{L}\right)$.

The first-order conditions are

$a f^{\prime}\left(a e_{L}\right)+\pi(a) a g\left(s-a\left(\theta e_{E}+e_{L}\right)\right)-c^{\prime}\left(e_{E}+e_{L}\right)=0$

$\theta \pi(a) \operatorname{ag}\left(s-a\left(\theta e_{E}+e_{L}\right)\right)-c^{\prime}\left(e_{E}+e_{L}\right)=0$.

The solutions to the first-order conditions (2a) and (2b) can be written $e_{L}\left(a, s, \pi_{0}, \theta\right)$ and $e_{E}\left(a, s, \pi_{0}, \theta\right)$, and the resulting expected test score is denoted

$T\left(a, s, \pi_{0}, \theta\right)=a\left(\theta e_{E}\left(a, s, \pi_{0}, \theta\right)+e_{L}\left(a, s, \pi_{0}, \theta\right)\right)$.

The second-order sufficient condition for a maximum is satisfied if the matrix $M$ of second partials is negative definite, where

$M=\left(\begin{array}{cc}a^{2} f^{\prime \prime}-\pi a^{2} g^{\prime}-c^{\prime \prime} & -\theta \pi a^{2} g^{\prime}-c^{\prime \prime} \\ -\theta \pi a^{2} g^{\prime}-c^{\prime \prime} & -\theta^{2} \pi a^{2} g^{\prime}-c^{\prime \prime}\end{array}\right)$.

The second-order condition implies that

$a^{2} f^{\prime \prime}-\pi a^{2} g^{\prime}-c^{\prime \prime}<0$

$D=a^{2} \pi g^{\prime}\left[(\theta-1)^{2} c^{\prime \prime}-a^{2} \theta^{2} f^{\prime \prime}\right]-a^{2} f^{\prime \prime} c^{\prime \prime}>0$

We assume throughout the paper that expressions (4a) and (4b) hold.

Combining the first-order conditions (2a) and (2b) yields the following:

$f^{\prime}\left(a e_{L}\right)=(\theta-1) \pi(a) g\left(s-a\left(\theta e_{E}+e_{L}\right)\right)$

This equation implies that if the individual's maximization problem possesses an interior solution, so that the chosen levels of $e_{L}$ and $e_{E}$ are both strictly positive, it must be the case that $\theta>1$. The reasoning is straightforward. An increase in $e_{L}$ impacts both the student's skill level and her probability of admission to college, while an increase in $e_{E}$ affects only the probability of admission. If $\theta \leq 1$, then $e_{E}$ is less effective than $e_{L}$ for improving test scores and the student would never devote effort to test preparation. The only reason that test preparation is attractive is because it is more effective than learning for improving entrance exam scores.

The distribution of aptitude is given by the function $H(a)$, with density function $h(a)$. Given the standard $s$, the other parameters of the model $\left(\pi_{0}\right.$ and $\left.\theta\right)$, and the two distribution functions ( $G$ and $H$ ), the mass of students admitted to college is given by

$A(s)=\int_{0}^{\infty}\left[1-G\left(s-T\left(a, s, \pi_{0}, \theta\right)\right)\right] h(a) d a$

Colleges are capacity constrained and can accommodate a fraction $r$ of the population. As a consequence, the standard $s$ satisfies $A(s)=r$.

\section{Aptitude, college admissions, and skill acquisition}

We begin analysis of the college admissions problem by describing behavior across aptitude levels. College admission is determined solely by test scores, and the first proposition characterizes the relationship between aptitude and expected test scores (all proofs are collected in Appendix A).

Proposition 1. Expected test scores increase with aptitude.

Since students are indexed by their aptitude, Proposition 1 identifies who is expected to go to college. According to the model expected test scores are governed in part by aptitude, but also by effort on learning and exam preparation. The proposition shows that, in equilibrium, exam preparation does not distort the relationship between aptitude and test scores, and the highest aptitude students are the ones expected to get into college.

Proposition 1 adds some structure to equilibrium. In particular, the fact that expected test scores increase with aptitude means that those above some threshold aptitude level $\bar{a}$ expect to be admitted (i.e. have an admission probability greater than one-half) and those below the threshold aptitude level expect to be denied admission, with $\bar{a}$ solving

$T\left(\bar{a}, s, \pi_{0}, \theta\right)=s$

Since $s-T\left(a, s, \pi_{0}, \theta\right)$ is decreasing in $a$ and $g\left(s-T\left(a, s, \pi_{0}, \theta\right)\right)$ is bell-shaped, we have $g^{\prime}>0$ for students with aptitude $a>\bar{a}$ and $g^{\prime}<0$ for students with aptitude $a<\bar{a}$.

If the college premium were the same for everyone who goes to college regardless of aptitude or skills, the question of who goes to college in and of itself would have no welfare implications. The real welfare question would have to do with skills. The ability to prepare for the tests leads students to devote effort to test preparation, but in equilibrium has no impact on who gets into college, and so the test preparation effort is socially wasteful. If students substitute test preparation for learning, skill acquisition is impacted. The next proposition describes this impact across aptitude levels.

Proposition 2. For the special case in which the college premium is independent of aptitude, skills increase with aptitude for students who expect to be admitted to college (i.e. $a>\bar{a}$ ) and decrease with aptitude for students who expect to be denied admission (i.e. $a<\bar{a}$ ). For the more likely case in which higher aptitude students enjoy larger college premiums, skills decrease with aptitude for students who expect to be denied admission (i.e. $a<\bar{a}$ ). 
Proposition 2 establishes that when the college premium is independent of aptitude, skill levels are a U-shaped function of aptitude, which is both surprising and troubling, particularly because it implies that the students with the lowest skills are the ones who are closest to the borderline for admission to college. The reason is clear. For these students studying for the test has the largest impact on whether they get into college and earn the college premium, and so they study the most for the test and exert the least effort toward learning. Since learning impacts productivity but test preparation does not, these borderline students have the lowest skills. In contrast, in a world without test preparation, the students with the lowest skills would be the ones with the lowest aptitude. $^{12}$

The U-shaped aptitude-skill profile only partially generalizes to the case where $\pi^{\prime}(a)>0$ as skills do not necessarily increase with aptitude for students who expect to be admitted to college. The reason for this is that among those who expect to be admitted, the higher aptitude ones, though surer of admission, may not want to substitute away from exam preparation and toward real learning any more than their lower aptitude counterparts because the stakes of getting in college are higher for the former.

Propositions 1 and 2 together imply very different pictures of the college population depending on whether one looks at skills or test scores. Of course, in expectation college-bound students have higher test scores than non-college-bound ones, and Proposition 1 confirms that these are also the students with the highest aptitude. So, in expectation the worst college-bound student has higher aptitude than the best non-college-bound student. On the other hand, Proposition 2 says that the lowestaptitude college-bound student has the same skills as the least-skilled non-college-bound student. The mostskilled college-bound student may have more skills than the most-skilled non-college-bound student, so the average skill level of college-bound students may exceed the average skill level of non-college-bound ones. The two skill ranges overlap, however, and from a skill perspective the college-bound may not look much different from the non-college bound. This would not be the case if the entrance examination were not coachable, because then both skills and expected test scores increase with aptitude, and the college-bound outperform the non-college bound on both measures of performance.

Propositions 1 and 2 also combine to yield our first version of the "high scores but low skills" phenomenon, and it applies for within-cohort comparisons. Specifically, for the group expecting to be denied admission, those with higher scores have lower skills. This is not, however, the "high scores but low skills" pattern that motivated the paper, as it does not apply to college students but instead to those who do not attend college.

\footnotetext{
12 All results for the scenario in which exam preparation is impossible can be found in Lemma 2 in Section 6.
}

\section{Increased access to college}

In a standard supply and demand analysis, increasing access to college increases the supply of college graduates but lowers the supply of high school graduates. Holding demand in the two markets constant, the increased access should lead to a lower wage for graduates and a higher wage for non-graduates, reducing inequality. Essentially, the inequality reduction comes through a reduced college premium as the increased number of college graduates compete it away.

Supply and demand analysis requires an endogenous college premium, which we do not have in this model. Nevertheless the same result, that increased college access reduces the wage disparity between high school and college graduates, would also obtain in our model if test preparation were prohibited. ${ }^{13}$ When college becomes more accessible those who were unlikely to be admitted before now find their chances of admission improved, and the payoff from increasing test scores rises. The only way to raise test scores when test preparation effort is impossible is through learning, which also raises skills, and so the increased accessibility makes lower aptitude students learn more and higher aptitude students learn less. This makes the skill levels more equal. And, unlike the supply and demand analysis, the inequality reduction here comes from more equal skills, not from a smaller college premium.

The next proposition explores the effects of increased college accessibility on both scores and skills when students can exert exam-specific effort. To begin, note from (1) that, given admission standard $s$, individual $a$ 's optimal choices of $e_{L}$ and $e_{E}$ do not depend on the college accessibility parameter $r$. Therefore, a change in college accessibility has effects on scores or skills only through a change in the admission standard. Intuitively, an increase in college accessibility would result in a lower equilibrium admission standard, which is formally stated as the following lemma.

Lemma 1. The equilibrium admission standard decreases with college accessibility.

Proposition 3. When college becomes more accessible expected test scores fall and skill levels rise for students who expect to be admitted to college (i.e. $a>\bar{a}$ ), while expected test scores rise and skill levels fall for students who expect to be denied admission (i.e. $a<\bar{a}$ ).

When college admissions are based on an exam for which students can prepare, increased accessibility to college leads to increased inequality in skills. The mechanism is as follows. When college is inaccessible, low-aptitude

\footnotetext{
13 Lemma 2 in Section 6 shows that when exam preparation is impossible, increased access to college leads to more learning and higher skills for low aptitude students and less learning and lower skills for high aptitude students. To the extent that skills translate into wages, this means that students who would already have expected to be admitted will reduce their skills and earn lower wages than before, and students who do not expect to gain admission under the new standard would have higher skills and higher wages than before the change. A true comparison of average wages between college-bound and non-college bound students, however, would depend on the nature of the distribution function $H(a)$ for aptitude levels.
} 
students are unlikely to get in, and so do not devote much effort to exam preparation. Instead, they devote it to learning, which increases their productivity. At the same time, high-aptitude students work hard to make sure they do get in, and so they have high test preparation effort and relatively low learning, which makes their productivity lower. But, when college becomes more accessible, those lowaptitude students suddenly have a better shot at getting into college and so move more of their effort into exam preparation. This lowers their productivity when they do not get into college. On the other hand, those high-aptitude students do not need to worry as much about getting in, and so they can devote less effort to test preparation and more to learning, and their productivity levels rise.

Proposition 3 establishes a mechanism through which a "high scores but low skills" can arise. If the population of students seeking college admission grows faster than the available seats, then Proposition 3 predicts that those who do get admitted will have higher scores but lower skills as college becomes less accessible. On the other hand, as the number of available spaces in college grows, students failing to gain admission will have higher scores than ever before but lower skills. Note that the "high scores but low skills" predictions here concern cross-cohort comparisons, where the distribution of aptitudes is assumed to stay the same over time. In contrast, the "high scores but low skills" prediction in the previous section used within-cohort comparisons.

\section{Effects of the college premium}

In this section we consider the effects of the average college premium $\pi_{0}$ on the two kinds of effort and hence on scores and skills. For simplicity, the result formally stated is partial equilibrium in nature in the sense that admissions standard is held constant. Nevertheless, some general equilibrium results can be immediately drawn based on the propositions derived here and in the last section concerning the effects of admissions standard (college accessibility).

Proposition 4. Hold the admissions standard constant. Then when the average college premium $\pi_{0}$ increases, examspecific effort increases, expected test scores increase, and real learning decreases.

Proposition 4 states that increases in the college premium make test scores rise but skill levels fall, which is the "high scores but low skills phenomenon." The result is a partial equilibrium result because of the assumption that the admissions standard does not rise when the college premium goes up. If the standard stays the same but test scores rise, more students are admitted to college and any college capacity constraint is violated. Combining Proposition 4 with Proposition 3 suggests that when the college premium rises and the required test score to get into college adjusts upward, the impact on skills is negative for high-aptitude students and ambiguous for low-aptitude students. Everyone learns less because of the wage premium effect which entices them to shift effort away from learning and toward exam preparation, and the higher admissions standard amplifies this effect for high-aptitude students as they fight for their seats at college. The total effect is ambiguous for low-aptitude students, though, because while the higher wage premium makes exam preparation more attractive, college is harder to get into making learning more attractive.

Combining Propositions 3 and 4 also suggests that when the college premium rises and the admissions standards goes up as a result, the equilibrium impact of an increase in college premium on expected test scores is positive for high-aptitude students and ambiguous for low-aptitude students. Taken together, the model predicts that, as college premium rises over time, college-going students have rising scores but falling skills over time.

\section{High scores but low skills}

We begin this section by considering an ideal world in which focused test preparation is impossible (no $e_{E}$ ) and test scores can be improved only through real learning. It can be shown that all the "abnormal results" obtained in previous sections are reversed and the high scores and low skills phenomenon, in each and every sense, would not occur.

Lemma 2. When exam preparation is impossible (so that $e_{E}$ is restricted to zero), higher aptitude students have both higher expected test scores and more skills. Furthermore, increased access to college leads to more learning and higher skills for low aptitude students and less learning and lower skills for high aptitude students. Finally, hold the admissions standard constant, increases in the average college premium lead to increases in learning and higher skills.

So far we have looked at who, as measured by aptitude, gets into college and how efforts to get into college impact skill acquisition for different aptitude levels. We have not, so far, explored whether efforts to get into college, in the form of preparing specifically for the entrance examination, lead to higher or lower skill levels overall. Instead, Propositions 1 and 2 only tell us that test scores rise with aptitude but skill levels do not, with the lowest skill levels coming from those closest to the college admissions threshold. Proposition 4 establishes that increases in the college premium drive test scores up but skill levels down, but the real issue is not whether an increase in the college premium exacerbates the high scores but low skills problem, but whether the ability to improve test scores through exam-specific effort leads to the problem in the first place.

The next proposition establishes fundamental cause for the high scores but low skills phenomenon, again in a partial equilibrium framework.

Proposition 5. Assume that the standard is held constant. For any individual, the existence of exam-specific effort leads to lower skills but higher expected test scores.

The proposition establishes that, fixing the admissions standard and any aptitude level, the individual exerts less effort toward learning but nevertheless earns higher test scores when test preparation is possible than when it is not. So, it is the ability to devote effort to test preparation that leads to the high scores but low skills phenomenon. 


\section{Conclusion}

Because colleges with limited spots want to admit students with high skills but cannot observe applicants' skills at the time of the admission decision, they must rely on a college entrance exam or a standardized test to screen applicants. In this paper, we have demonstrated that admission policies based solely on scores on a college entrance examination, such as those in Austria, China, and Ireland, leads to a "high scores but low skills" phenomenon: compared to a scenario in which the entrance examinations are not coachable, the ability to study explicitly for the college entrance examination leads to higher test scores but lower skills at all aptitude levels. This reduction in skills occurs because students substitute effort away from real learning and toward exam preparation, and this takes place even though the ability to prepare for the exam has no impact on who gets into college, in equilibrium.

The across-the-board reduction in skill levels is troubling, if only because it reduces a country's productivity and competitiveness. The ability to prepare for entrance exams has other worrisome implications, as well. First, it changes the monotone relationship between aptitude and skills. Without exam preparation higher aptitude students have higher skills, but with exam preparation the lowest skills are obtained by students close to the borderline for college admission. The intuition behind this result is straightforward: borderline students have the most to gain from exam preparation, and so they do the most of it, neglecting real learning in the process. This U-shaped skills/aptitude pattern leads to an enhanced "high scores but low skills" effect among students actually enrolled in college, because the students who were barely admitted are among the least skilled in the entire applicant pool. ${ }^{14}$

Another worrisome implication concerns the ability of an increase in access to higher education to equalize incomes across the population. When students cannot prepare for the examination, increasing access leads to more skill acquisition among low-aptitude students and less skill acquisition among high-aptitude students, leading to less inequality between college graduates and non-graduates. When students can prepare for the college entrance examination, on the other hand, this pattern is reversed, and increased access leads to greater income inequality.

These results were derived under the assumption of a single test-score cutoff for admission, and a single college premium function for all students. ${ }^{15}$ In reality, however, there are more selective and less selective colleges with the former having higher cutoff scores and larger college premiums. Further research is required to determine how

\footnotetext{
14 While the U-shaped distribution of the skills-aptitude relationship comes naturally from our model and seems intuitive to us, we are unaware of any empirical evidence for it in the literature. Furthermore, our results suggest that such an empirical exercise would be problematic, because the standard way of measuring any attribute, including both skills and aptitude, for high school students is with standardized tests, and the results show that test scores rise with aptitude.

15 Our model also assumes that the college premium depends only on aptitude effectively makes it exogenous. An interesting extension would allow college premium to increase in skills accumulated before college.
}

students behave when different colleges have different levels of selectivity, since the same student might apply to several different colleges with different admissions standards and, thus, have a small chance of gaining admission to the most selective college but a very high probability of admission to the least selective one. It is unclear how these considerations will impact the U-shaped skills curve derived here. However, the single-college model may gain more traction when one considers small geographic regions, as Alm and Winters (2009) find that students are more likely to enroll in closer colleges, and so the model might apply to the primary college in an appropriate region.

The findings of this paper suggest that a welfare improvement, caused by an across-the-board increase in skill levels, could be obtained if college admission policies were changed so that exam preparation were impossible, or at least less effective in raising scores. ${ }^{16}$ It should be noted, though, that while the analysis in the paper only concerns test preparation, it could be extended to other factors that improve chances of admission with only a tenuous impact on skills, such as overzealous participation in extracurricular activities. ${ }^{17}$ However, it is in no way clear how to make college admissions less dependent on an entrance examination or a standardized test. For example, GPAs are not comparable across schools, and focusing on them may cause grade inflation. ${ }^{18}$ Essays and recommendation letters are subjective and are costly to evaluate. More importantly, allowing less objective criteria than test scores may induce rent-seeking behavior by admission officers and could be the grounds for corruption. For those countries that rely solely on college entrance examination scores to assign college seats, they may well have adopted the fairest and the most efficient college admission policy, given the prevailing culture and institutions, even though the high scores but low skills problem is an inevitable consequence of such a policy.

\section{Appendix A.}

Lemma 1. Using the same comparative statics approach as in the other proofs, we can find

$$
\begin{aligned}
& \frac{d e_{L}}{d s}=-\frac{\pi a g^{\prime}}{D}(\theta-1) c^{\prime \prime}, \\
& \frac{d e_{E}}{d s}=\frac{\pi a g^{\prime}}{D}\left[(\theta-1) c^{\prime \prime}-\theta a^{2} f^{\prime \prime}\right],
\end{aligned}
$$

\footnotetext{
${ }^{16}$ Actual welfare results are hard to obtain in a general equilibrium model with students of different aptitudes. For example, as $\theta$ decreases making the test less coachable, and $s$ also decreases to account for the lower test scores, not all students will be made better off. In contrast, we can show that a decrease in $\theta$ accompanied by a general equilibrium decrease in $s$ would unambiguously improve welfare if all students had the same aptitude.

${ }^{17}$ Lipscomb (2007) finds that participation in extracurricular activities is associated with higher standardized test scores.

18 Grant (2007) finds that higher grades in micro principles courses are not indicators of higher productivity, but rather indicators of something else, providing another reason why GPAs may not be the best factor to use for admissions.
} 
and

$$
\begin{gathered}
\frac{d T}{d s}=a \theta \frac{d e_{E}}{d s}+a \frac{d e_{L}}{d s} \\
=\frac{\pi a^{2} g^{\prime}}{D}\left[(\theta-1)^{2} c^{\prime \prime}-\theta^{2} a^{2} f^{\prime \prime}\right] . \\
=\frac{\pi a^{2} g^{\prime}\left[(\theta-1)^{2} c^{\prime \prime}-\theta^{2} a^{2} f^{\prime \prime}\right]}{\pi a^{2} g^{\prime}\left[(\theta-1)^{2} c^{\prime \prime}-\theta^{2} a^{2} f^{\prime \prime}\right]-a^{2} f^{\prime \prime} c^{\prime \prime}}<1 .
\end{gathered}
$$

College becomes more accessible when $r$ increases. To assess the impact on the equilibrium admission standard $s$ of an increase in $r$, differentiate the expression $A(s)=r$ at the end of Section 2 with respect to $r$, which yields

$-\int g\left(s-T\left(a, s, \pi_{0}, \theta\right)\right)\left[\frac{d s}{d r}-\frac{d T\left(a, s, \pi_{0}, \theta\right)}{d s} \frac{d s}{d r}\right] h(a) d a=1$.

Rearranging yields

$\frac{d s}{d r}=\frac{1}{\int g\left(s-T\left(a, s, \pi_{0}, \theta\right)\right)[d T / d s-1] h(a) d a}$.

By the last line of $(\mathrm{A} 1)$ we have $\mathrm{d} T / \mathrm{d} s<1$ for all $a$. Therefore, $s$ decreases when $r$ increases.

Lemma 2. Rewrite the objective function in (1) to preclude the possibility of test preparation effort:

$\left.f\left(a e_{L}\right)+\pi(a)\left[1-G\left(s-a e_{L}\right)\right)\right]-c\left(e_{L}\right)$.

The first-order condition is

$a f^{\prime}\left(a e_{L}\right)+\pi(a) a g\left(s-a e_{L}\right)-c^{\prime}\left(e_{L}\right)=0$,

and the second-order condition is

$a^{2} f^{\prime \prime}-\pi a^{2} g^{\prime}-c^{\prime \prime}<0$

which is guaranteed by (4a). Let $e_{L}{ }^{*}$ denote the solution to (A3), and let $T^{*}$ denote the corresponding expected test score given by $T^{*}=a e_{L}{ }^{*}$. Both are functions of $a, s$, and $\pi_{0}$. We get

$\frac{d T^{*}}{d a}=\frac{a f^{\prime}+c^{\prime \prime} e_{L}^{*}+\pi a g+a^{2} \pi^{\prime} g}{c^{\prime \prime}+\pi a^{2} g^{\prime}-a^{2} f^{\prime \prime}}>0$,

which establishes that expected test scores increase with aptitude. Also,

$$
\begin{gathered}
\frac{d f\left(a e_{L}{ }^{*}\right)}{d a}=e_{L}{ }^{*} f^{\prime}+a \frac{d e_{L}{ }^{*}}{d a} f^{\prime} \\
=\frac{a f^{\prime}+c^{\prime \prime} e_{L}{ }^{*}+\pi a g+a^{2} \pi^{\prime} g}{c^{\prime \prime}+\pi a^{2} g^{\prime}-a^{2} f^{\prime \prime}} f^{\prime}>0,
\end{gathered}
$$

which implies that higher aptitude students obtain higher skills.

One can compute

$$
\frac{d e_{L}^{*}}{d s}=\frac{\pi a g^{\prime}}{c^{\prime \prime}+\pi a^{2} g^{\prime}-a^{2} f^{\prime \prime}}
$$

This derivative has the same sign as $g^{\prime}$, so is positive when $a>\bar{a}$ and negative when $a<\bar{a}$. Consequently, reducing the standard (or increased access to college) leads to more learning and higher skills for low-aptitude students and less learning and lower skills for high-aptitude students.
Finally,

$\frac{d e_{L}^{*}}{d \pi_{0}}=\frac{a g}{c^{\prime \prime}+\pi a^{2} g^{\prime}-a^{2} f^{\prime \prime}} \geq 0$,

so increasing the college premium leads to more learning and higher skills.

Proposition 1. Differentiating the first-order conditions with respect to a yields, in matrix form,

$M\left(\begin{array}{c}d e_{L} / d a \\ d e_{E} / d a\end{array}\right)$
$=\left(\begin{array}{c}-f^{\prime}-a e_{L} f^{\prime \prime}-\left(\pi^{\prime} a+\pi\right) g+\left(\theta e_{E}+e_{L}\right) \pi a g^{\prime} \\ -\theta\left(\pi^{\prime} a+\pi\right) g+\left(\theta e_{E}+e_{L}\right) \theta \pi a g^{\prime}\end{array}\right)$,

where the matrix $M$ is given in (3). By expression (5) we have $f^{\prime}=(\theta-1) \pi g$, and substituting this into the above expression yields

$$
\begin{aligned}
& M\left(\begin{array}{c}
d e_{L} / d a \\
d e_{E} / d a
\end{array}\right) \\
& =\left(\begin{array}{c}
-(\theta-1) \pi g-a e_{L} f^{\prime \prime}-\left(\pi^{\prime} a+\pi\right) g+\left(\theta e_{E}+e_{L}\right) \pi a g^{\prime} \\
-\theta\left(\pi^{\prime} a+\pi\right) g+\left(\theta e_{E}+e_{L}\right) \theta \pi a g^{\prime}
\end{array}\right) .
\end{aligned}
$$

Solving and simplifying yields

$$
\begin{aligned}
\frac{d e_{L}}{d a}= & \frac{1}{D}\left\{a e_{L} f^{\prime \prime}\left(\theta^{2} \pi a^{2} g^{\prime}+c^{\prime \prime}\right)\right. \\
& +(\theta-1) a c^{\prime \prime}\left[\left(\theta e_{E}+e_{L}\right) \pi g^{\prime}-\pi^{\prime} g\right] \\
& \left.+(\theta-1) \theta^{2} \pi^{2} a^{2} g^{\prime} g\right\}
\end{aligned}
$$

$$
\begin{aligned}
& \text { and } \\
& \begin{aligned}
\frac{d e_{E}}{d a}= & \frac{1}{D}\left\{-a e_{L} f\left(\theta \pi a^{2} g^{\prime}+c\right)+(\theta-1) c^{\prime \prime}\left[\pi^{\prime} a g\right.\right. \\
& \left.-\left(\theta e_{E}+e_{L}\right) \pi a g^{\prime}\right]-(\theta-1) \theta \pi^{2} a^{2} g g^{\prime} \\
& \left.+a^{2} f^{\prime \prime}\left[-\left(\pi^{\prime} a+\pi\right) \theta g+\left(\theta e_{E}+e_{L}\right) \theta \pi a g^{\prime}\right]\right\} .
\end{aligned}
\end{aligned}
$$

Since the expected test score is

$T=a\left(\theta e_{E}+e_{L}\right)$,

we have

$\frac{d T}{d a}=a\left(\theta \frac{d e_{E}}{d a}+\frac{d e_{L}}{d a}\right)+\left(\theta e_{E}+e_{L}\right)$

which simplifies to

$$
\begin{aligned}
\frac{d T}{d a}= & \frac{1}{D}\left\{-a^{2} \theta f^{\prime \prime}\left[c^{\prime \prime}\left(e_{L}+e_{E}\right)+\theta\left(\pi^{\prime} a+\pi\right) a g\right]\right. \\
& \left.+(\theta-1)^{2} a^{2} \pi^{\prime} g c^{\prime \prime}\right\}>0
\end{aligned}
$$

Proposition 2. From (5), $f\left(a e_{L}\right)=(\theta-1) \pi(a) g\left(s-a\left(\theta e_{E}+\right.\right.$ $\left.e_{L}\right)$ ), we have

$\frac{d f^{\prime}\left(a e_{L}\right)}{d a}=(\theta-1) \pi^{\prime} g+(\theta-1) \pi\left[-\left(\theta e_{E}+e_{L}\right)-\frac{d T}{d a}\right] g^{\prime}$

If the college premium is independent of aptitude $\left(\pi^{\prime}=0\right)$, the derivative has the opposite sign as $g^{\prime}$ because $d T / d a>0$ from Proposition 1 . Therefore, given the concavity of $f$, skills $\left(a e_{L}\right)$ increase with aptitude when $g^{\prime}>0$, which 
occurs when $a>\bar{a}$, and decrease with aptitude when $g^{\prime}<0$, which occurs when $a<\bar{a}$.

If the college premium increases in aptitude $\left(\pi^{\prime}>0\right)$, the derivative has a definite sign (positive) only when $g^{\prime}<0$. Therefore, skills decrease with aptitude when $g^{\prime}<0$, which occurs when $a<\bar{a}$.

Proposition 3. From Lemma 1, college becoming more accessible implies a decrease in the admission standard. The impact of this decrease on expected scores is determined by, from (A1),

$\frac{d T}{d s}=\frac{\pi a^{2} g^{\prime}}{D}\left[(\theta-1)^{2} c^{\prime \prime}-\theta^{2} a^{2} f^{\prime \prime}\right]$

The sign of the derivative is the same as the sign of $g^{\prime}$, and so the effect of increased access has the opposite sign of $g^{\prime}$. We know that $g^{\prime}>0$ when $a>\bar{a}$ and $g^{\prime}<0$ when $a<\bar{a}$. Hence, expected scores decrease with access when $a>\bar{a}$ and increase with access when $a<\bar{a}$.

The impact of the decrease in the admissions standard on skills is determined by

$\frac{d f\left(a e_{L}\right)}{d s}=a \frac{d e_{L}}{d s} f^{\prime}=-\frac{\pi a^{2} g^{\prime}}{D}(\theta-1) c^{\prime \prime} f^{\prime}$.

The sign of the derivative is the opposite of the sign of $g^{\prime}$, and so the effect of increased access has the same sign as $g^{\prime}$. We know that $g^{\prime}>0$ when $a>\bar{a}$ and $g^{\prime}<0$ when $a<\bar{a}$. Hence, skills increase with access when $a>\bar{a}$ and decrease with access when $a<\bar{a}$.

Proposition 4. The comparative statics derivatives $d e_{L} / d \pi_{0}$ and $d e_{E} / d \pi_{0}$ are given by the system

$M\left(\begin{array}{c}d e_{L} / d \pi_{0} \\ d e_{E} / d \pi_{0}\end{array}\right)=\left(\begin{array}{c}-a g \\ -\theta a g\end{array}\right)$,

where the matrix $M$ is given by (3). Solving yields
As for the expected test score,

$$
\begin{gathered}
\frac{d T}{d \pi_{0}}=\theta a \frac{d e_{E}}{d \pi_{0}}+a \frac{d e_{L}}{d \pi_{0}} \\
=\frac{a^{2} g}{D}\left[(\theta-1)^{2} c^{\prime \prime}-\theta^{2} a^{2} f^{\prime \prime}\right]>0 .
\end{gathered}
$$

Proposition 5. Let $e_{L}{ }^{*}, e_{E}{ }^{*}$, and $T^{*}$ be as defined in the proof of Lemma 2, and these values pertain to the case in which exam-specific effort is prohibited. Choose any individual and hold that individual's aptitude constant at $a$. Note that using a single value of $\pi$ instead of a function $\pi(a)$ is legitimate when $a$ is held fixed. Write $e_{L}$, and $e_{L}{ }^{*}$ as functions of $\pi$. When $\pi=0$, exam-specific learning serves no purpose and $e_{E}=0$. The choice of $e_{L}$ is then the same as it would be if exam-specific effort was prohibited, so $e_{L}(0)=e_{L}{ }^{*}(0)$. By Proposition 4 and Lemma $1, d e_{L}(\pi) / d \pi<0<d e_{L}{ }^{*}(\pi) / d \pi$ for all $\pi \geq 0$. Then

$e_{L}(\pi)-e_{L}^{*}(\pi)=\int_{0}^{\pi}\left[\frac{d e_{L}(z)}{d z}-\frac{d e_{L}^{*}(z)}{d z}\right] d z<0$

for all $\pi>0$. It follows that $f\left(a e_{L}\right) \leq f\left(a e_{L}{ }^{*}\right)$, and skills are lower when exam-specific effort is allowed.

Similarly, let $T(\pi)$ and $T^{*}(\pi)$ be the expected test scores when exam-specific effort is allowed and prohibited, respectively. Then $T(0)=T^{*}(0)$ since $e_{E}=0$ and $e_{L}=e_{L}{ }^{*}$ when $\pi=0$. Furthermore, $d e_{L} / d x$ and $d e_{E} / d x$ are given by the system (A5), and solving for $d e_{E} / d \pi$ yields

$$
\frac{d e_{E}}{d \pi}=\frac{1}{D}\left[-a g\left(c^{\prime \prime}+\theta \pi a^{2} g^{\prime}\right)+\theta a g\left(c^{\prime \prime}+\pi a^{2} g^{\prime}-a^{2} f^{\prime \prime}\right)\right],
$$

which can be rearranged to generate

$$
\frac{\theta a g}{D}=\left[\frac{1}{c^{\prime \prime}+\pi a^{2} g^{\prime}-a^{2} f^{\prime \prime}}\right] \cdot \frac{d e_{E}}{d \pi}+\frac{a g}{D} \cdot\left[\frac{c^{\prime \prime}+\pi a^{2} g^{\prime}}{c^{\prime \prime}+\pi a^{2} g^{\prime}-a^{2} f^{\prime \prime}}\right] .
$$

Solving (A5) for $d e_{L} / d \pi$ yields

$$
\begin{aligned}
\frac{d e_{L}}{d \pi} & =\frac{a g}{D}\left(c^{\prime \prime}+\theta^{2} \pi a^{2} g^{\prime}\right)-\frac{\theta a g}{D}\left(c^{\prime \prime}+\theta \pi a^{2} g^{\prime}\right) \\
& =\frac{a g}{D}\left[\left(c^{\prime \prime}+\theta^{2} \pi a^{2} g^{\prime}\right)-\frac{\left(c^{\prime \prime}+\theta \pi a^{2} g^{\prime}\right)^{2}}{c^{\prime \prime}+\theta \pi a^{2} g^{\prime}-a^{2} f^{\prime \prime}}\right]-\left[\frac{c^{\prime \prime}+\theta \pi a^{2} g^{\prime}}{c^{\prime \prime}+\theta \pi a^{2} g^{\prime}-a^{2} f^{\prime \prime}}\right] \cdot \frac{d e_{E}}{d \pi} \\
& =\frac{a g}{D}\left[\frac{D}{c^{\prime \prime}+\theta \pi a^{2} g^{\prime}-a^{2} f^{\prime \prime}}\right]-\left[\frac{c^{\prime \prime}+\theta \pi a^{2} g^{\prime}}{c^{\prime \prime}+\theta \pi a^{2} g^{\prime}-a^{2} f^{\prime \prime}}\right] \cdot \frac{d e_{E}}{d \pi} \\
& =\frac{d e_{L}{ }^{*}}{d \pi}-\left[\frac{c^{\prime \prime}+\theta \pi a^{2} g^{\prime}}{c^{\prime \prime}+\theta \pi a^{2} g^{\prime}-a^{2} f^{\prime \prime}}\right] \cdot \frac{d e_{E}}{d \pi} .
\end{aligned}
$$

The derivative with respect to test scores can be written

$\frac{d e_{L}}{d \pi_{0}}=-\frac{1}{D}(\theta-1) a g c^{\prime \prime}<0$

and

$\frac{d e_{E}}{d \pi_{0}}=\frac{a g}{D}\left[(\theta-1) c^{\prime \prime}-\theta a^{2} f^{\prime \prime}\right]>0$.

$$
\begin{gathered}
\frac{d T}{d \pi}=a\left[\theta-\frac{c^{\prime \prime}+\theta \pi a^{2} g^{\prime}}{c^{\prime \prime}+\pi a^{2} g^{\prime}-a^{2} f^{\prime \prime}}\right] \frac{d e_{E}}{d \pi}+a \frac{d e_{L}{ }^{*}}{d \pi} \\
=a \frac{(\theta-1) c^{\prime \prime}-\theta a^{2} f^{\prime \prime}}{c^{\prime \prime}+\pi a^{2} g^{\prime}-a^{2} f^{\prime \prime}} \cdot \frac{d e_{E}}{d \pi}+a \frac{d e_{L}{ }^{*}}{d \pi} \\
>a \frac{d e_{L}{ }^{*}}{d \pi}=\frac{d T^{*}}{d \pi} .
\end{gathered}
$$


Thus

$T(\pi)-T^{*}(\pi)=\int_{0}^{\pi}\left[\frac{d T(z)}{d z}-\frac{d T^{*}(z)}{d z}\right] d z>0$

for all $\pi>0$, and test scores are higher when exam-specific effort is allowed.

\section{References}

Alm, J., \& Winters, J. V. (2009). Distance and intrastate college student migration. Economics of Education Review, 28(6), 728-738.

Baker, G. (2002). Distortion and risk in optimal incentive contracts. Journal of Human Resources, 37(4), 728-751.

Bound, J., Hershbein, B., \& Long, B. T. (2009). Playing the admissions game: Student reactions to increasing college competition. Journal of Economic Perspectives, 23(4), 119-146.

Burger, J. M., \& Krueger, M. (2003). A balanced approach to high-stakes achievement testing: An analysis of the literature with policy implications. International Electronic Journal for Leadership in Learning, 7(4.). http://www.ucalgary.ca/ iejll

DeAngelo, L., Hurtado, S., Pryor, J. H., Kelly, K. R., Santos, J. L., \& Korn, W. S. (2009). The American college teacher: National norms for the 2007-2008 HERI Faculty Survey. Higher Education Research Institute at UCLA.

Epple, D., Romano, R., Sarpça, S., \& Sieg, H. (2006). Profiling in bargaining over college tuition. Economic Journal, 116(515), F459-F479.

Epple, D., Romano, R., \& Sieg, H. (2002). On the demographic composition of colleges and universities in market equilibrium. American Economic Review, 92(2), 310-314.

Epple, D., Romano, R., \& Sieg, H. (2003). Peer effects, financial aid and selection of students into colleges and universities: An empirical analysis Journal of Applied Econometrics, 18, 503-525.

Epple, D., Romano, R., \& Sieg, H. (2006). Admission, tuition, and financial aid policies in the market for higher education. Econometrica, 74(4), 885-928.

Epple, D., Romano, R., \& Sieg, H. (2008). Diversity and affirmative action in higher education. Journal of Public Economic Theory, 10(4), 475-501.
Fang, H. (2006). Disentangling the college wage premium: Estimating a model with endogenous education choices. International Economic Review, 47(4), 1151-1185.

Grant, D. (2007). Grades as information. Economics of Education Review, 26(2), 201-214.

Grogger, J., \& Eide, E. (1995). Changes in college skills and the rise in the college wage premium. Journal of Human Resources, 30, 280-310.

Groot, W., \& Oosterbeek, H. (1994). Earnings effects of different components of schooling: Human capital versus screening. Review of Economics and Statistics, 76(2), 317-321.

Helms, R. M. (2008). University Admissions Worldwide. World Bank Education Working Paper 15.

Holmstrom, B., \& Milgrom, P. (1991). Multitask principal-agent analyses: Incentive contracts, asset ownership, and job design. Journal of Law, Economics, and Organization, 7, 24-52.

Hoxby, C. M. (2009). The changing selectivity of American colleges. Journal of Economic Perspectives, 23(4), 95-118.

Kelly, E., O'Connell, P.J., \& Smyth, E. (2010). The economic returns to field of study and competencies among higher education graduates in Ireland. Economics of Education Review, 29(4), 650-657.

Lazear, E. P.(2006). Speeding, terrorism, and teaching to the test, quarterly. Journal of Economics, 121(3), 1029-1061.

Li, L. (2005). Education for 1.3 billion. China: Foreign Language Teaching and Research Press, and Pearson Education Asia Ltd.

Lipscomb, S. (2007). Secondary school extracurricular involvement and academic achievement: A fixed effects approach. Economics of Education Review, 26(4), 463-472.

National Center for Educational Statistics (2006). A first look at the literacy of America's adults in the 21st century. NCES 2006-470.

Ockert, B. (2010). What's the value of an acceptance letter? Using admissions data to estimate the return to college. Economics of Education Review, 29(4), 504-516.

Pryor, J. H., Hurtado, S., DeAngelo, L., Sharkness, J., Romero, L. C., Korn, W. S., et al. (2008). The American freshman: National norms fall 2008. Higher Education Research Institute at UCLA.

Smith, M. L., \& Fey, P. (2000). Validity and accountability of high-stakes testing. Journal of Teacher Education, 51(5), 334-344.

Weiss, A. (1995). Human capital vs. signaling explanations of wages. Journal of Economic Perspective, 9(4), 133-154.

Yakusheva, O. (2010). Return to college education revisited: Is relevance relevant? Economics of Education Review, 29(6), 1125-1142. 